OPEN ACCESS

Edited by:

Hiba Baroud,

Vanderbilt University, United States

Reviewed by:

Hemen Mark Butu,

Kyungpook National University,

South Korea

Guicai Ning,

The Chinese University of Hong Kong, Hong Kong SAR, China

Jim Rossi,

Vanderbilt University, United States

*Correspondence:

Sonya Ziaja

sziaja@ubalt.edu

Specialty section:

This article was submitted to

Climate Risk Management,

a section of the journal

Frontiers in Climate

Received: 31 May 2021 Accepted: 22 September 2021 Published: 03 December 2021

Citation:

Ziaja S and Chhabra M (2021) Climate Adaption for Energy Utilities: Lessons Learned From California's Pioneering Regulatory Actions.

Front. Clim. 3:718472.

doi: 10.3389/fclim.2021.718472

\section{Climate Adaption for Energy Utilities: Lessons Learned From California's Pioneering Regulatory Actions}

\author{
Sonya Ziaja ${ }^{1 *}$ and Mohit Chhabra ${ }^{2}$ \\ ${ }^{1}$ University of Baltimore School of Law, Baltimore, MD, United States, ${ }^{2}$ Natural Resources Defense Council, San Francisco, \\ CA, United States
}

This Policy Brief provides lessons learned from regulation of climate adaptation by energy utilities. The regulatory bodies responsible for oversight of investor-owned energy utilities are ill-equipped to regulate climate adaptation in the energy sector; but they may be the only institutions with authority to do so. In 2018, the California Public Utilities Commission initiated the first quasi-legislative procedure to regulate investor owned energy utilities' climate adaptation activities. The Commission's new rules for climate adaptation offer some general guidance on climate adaptation, and require investor owned utilities to conduct and submit climate vulnerability studies. Structural limitations, including conflicting interest, capacity of staff, and scope of the problem hampered the success of adaptation regulation, which failed to address fundamental questions about what constitutes adaptive measures.

Keywords: climate adaptation, energy, private utilities, regulation, California

\section{INTRODUCTION}

The regulatory bodies responsible for oversight of investor-owned energy utilities are ill-equipped to regulate climate adaptation in the energy sector, but may be the only institutions best suited, and with authority, to do so. The California Public Utilities Commission (Commission) issued the first climate adaptation regulations for regulated energy utilities in 2020-recommending scientific tools, standards, and decision-making process; and requiring the three largest private utilities in California to undertake climate vulnerability assessments with a vulnerable community engagement component. The Commission convened a multi-stakeholder working group to advise on its initial approach to adaptation regulation. While there were notable successes to the Commission's approach, significant structural limitations hampered the Commission's process and the outcome of the regulatory proceeding. This policy commentary presents an overview of this first attempt in the United States to formally regulate climate adaptation processes for private energy utilities, from the perspective of two of the working group participants, and presents recommendations for future regulation of climate adaptation by private energy utilities ${ }^{1}$.

\footnotetext{
${ }^{1}$ Mohit Chhabra is a Senior Scientist with the Natural Resources Defense Council. He participated in the Commission's Climate Adaptation proceeding from 11/2018 to 02/2020. Sonya Ziaja is an Assistant Professor of Law at the University of Baltimore; from July 2020; she was an analyst at the Public Advocates Office of the California Public Utilities Commission and participated in the proceeding from 05/2018 to 02/2020; from 08/2014 to 12/2017 she was the Research Lead for the Water-Energy-Climate Nexus at the California Energy Commission, and was part of the team of staff responsible for the Integrated Energy Policy Report chapters on Climate Adaptation, which required consultation with the Commission. The opinions expressed in this policy brief represent those of the authors and do not represent their current or former employers.
} 


\section{CLIMATE CHANGE IMPACTS ON THE ENERGY SECTOR}

Climate change affects all aspects of the energy sector: energy production, consumption, transmission, and distribution. Researchers at the California Energy Commission estimate that the demand for electricity to cool homes could increase around 5\% compared to historical levels by 2030 (Franco and Sanstad, 2008). More extreme heat events mean that electric demand for cooling on especially hot days would increase even more as shown in Figure 1 (Auffhammer et al., 2017). This effect will be magnified in areas that already have very hot summers, like Los Angeles and Sacramento. And it is in these areas where almost half of California's disadvantaged communities ${ }^{2}$, many of which cannot afford to meet their basic energy needs, are located. These communities will be challenged to meet increased energy needs because lower income households tend to be poorly insulated and often don't have efficient cooling equipment. Meeting these increased energy needs means increased utility bills for these communities.

In late August 2020, a heat wave settled across the Western United States. It brought power shortages with it. As overheated homes and businesses turned up their ACs, demand for electricity exceeded available supply. Under normal conditions, energy hungry states could temporarily import electricity from their neighbors to avert power shortages. In this case, states like California could not import electricity, because its neighbors faced the same conditions. Extreme heat days have already increased $^{3}$ in the region and heat waves are expected to get longer, more frequent, and more severe ${ }^{4}$.

Climate change also impacts the amount of electricity renewables produce and when they produce electricity. For example, extreme heat reduces the efficiency of solar panels and changing precipitation patterns affect how much hydroelectric power is available at any given time. These changes in electricity production patterns and demand, both caused by the climate crisis, can compound to make it harder to serve California's clean energy needs.

California makes use of excess hydropower from the Northwest to meet its clean energy needs. Seattle City Light's power planners recently found climate change is causing electricity demand in their service territory to increase in the summer; at the same time, decreased snowpack and changing precipitation patterns are decreasing available hydroelectric generation capacity. ${ }^{5}$ The Pacific Northwest already depends on hydropower for around half of its energy needs. Seattle City Light must now plan to meet this increased without relying on fossil

\footnotetext{
${ }^{2}$ Disadvantaged communities are an official designation of California's Environmental Protection Agency for identifying vulnerable communities based on demographic and environmental factors. California Office of Environmental Health Hazard Assessment (2017).

${ }^{3}$ California Office of Environmental Health Hazard Assessment (2019).

${ }^{4}$ Cal-Adapt. Extreme Heat Days \& Warm Nights. Available online at: https://caladapt.org/tools/extreme-heat/ (accessed May 21, 2021).

${ }^{5}$ Seattle City Light (2015).
}

generation to avoid further contributing to climate change and to comply with the state of Washington's carbon reduction goals ${ }^{6}$.

Finally, climate change also impacts utility infrastructure. Recent wildfires in California, some of which were ignited when high voltage transmission lines interacted with dry vegetation ${ }^{7}$, are a prominent example. Increasingly hotter and drier summers, again due to climate change, mean conditions conducive to deadly wildfires which also have immense financial implications that include a $\$ 21$ billion wildfire safety fund that will be developed from the utility's electricity customers ${ }^{8}$. This alone is expected to increase electric rates by at least $\sim 19$ cents/kWh or around $75 \%$ in Pacific Gas and Electric service territory (Chhabra and Hay, 2020).

Higher temperatures also impact the performance of electric transformers and substations (Burillo et al., 2019); electricity losses from transmission and distribution cables increase as it gets hotter; sea level rise threatens substations near the coast ${ }^{9}$; and climate change is expected to cause disruptions to and the need for repair of fossil gas infrastructure.

\section{HOW CAN THE ENERGY SECTOR ADAPT TO THESE IMPACTS?}

Ameliorating climate impacts to the energy sector, requires funding and expertise go beyond "business as usual" planning. Utilities need climate-relevant expertise to identify infrastructure and system upgrades, operational changes, and develop adaptation solutions; regulators need this expertise to understand whether investor-owned utility (IOU) proposed upgrades are prudent. IOU shareholders make profits on infrastructure investments (such as constructing new substations and transmission lines), not on operational spending (better maintenance of existing infrastructure). Regulators need to understand what investments are most cost-effective to mitigate climate threat while delivering clean and reliable power to be able to assess IOU upgrade proposals and to proactively guide climate adaptation efforts by IOUs.

Adaptation measures require investment. Some, such as "hardening" of transmission infrastructure to reduce wildfires, require billions of dollars of investment. Under the current ratemaking structure, each investment results in increased rates. Even though some of these investments are necessary to prevent much greater costs that come with climate damage, this poses a unique challenge for regulators, especially those with a duty to ensure electricity is affordable.

Finally, keeping electricity affordable is essential to mitigating climate change. A key component of climate change mitigation is displacement of fossil fuels by clean electricity (e.g., switching to electric cars and all electric buildings from fossil fuel powered ones), this requires that electricity remain an affordable

\footnotetext{
${ }^{6}$ Department of Ecology, State of Washington. Reducing Greenhouse Gases. Available online at: https://ecology.wa.gov/Air-Climate/Climate-change/ Greenhouse-gases/Reducing-greenhouse-gases (accessed May 21, 2021).

${ }^{7}$ National Public Radio (2019).

${ }^{8}$ Natural Resources Defense Council (2019).

${ }^{9}$ Pacific Gas Electric Company (2016).
} 


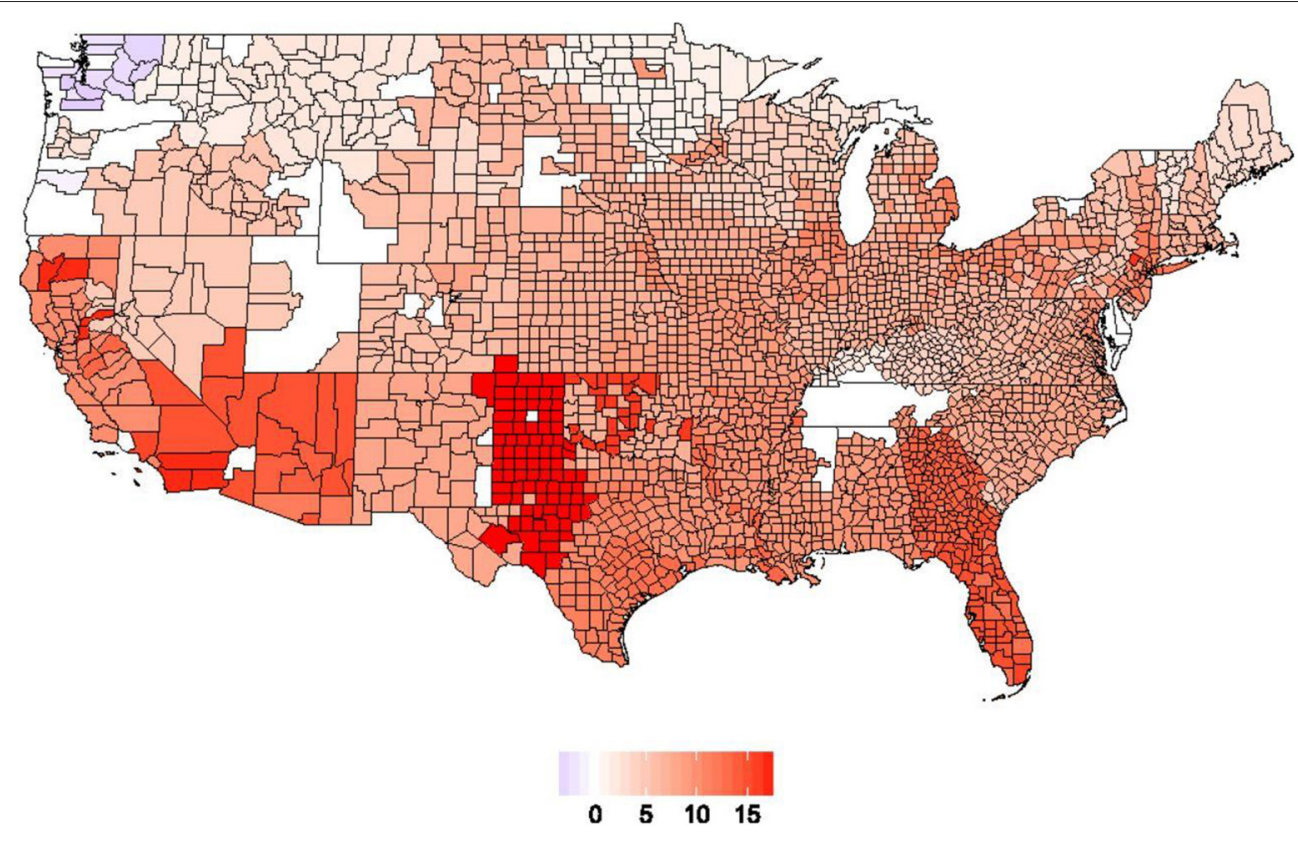

FIGURE 1 | Changes in Peak Load Under RCP8.5 Scenario Across the United States. Peak Load Varies Geographically, with the Largest Increases in the South and West. Coloring Reflects the Percentage Increases in Peak Load due to Temperature Rise by the End of the Century (Auffhammer et al., 2017).

alternative to other fuels. Currently electric prices are already comparable with gasoline and natural gas prices in California. If electricity prices increase at a faster rate than polluting alternatives, then electricity won't remain a viable alternative.

For a regulator to oversee climate adaptation by utilities in a way that allows for investment while keeping energy affordable, commissions first need to establish standards for determining what constitutes adaptive measures. Without such standards, financing for climate adaptation is ad hoc-leaving open the possibilities of being over inclusive (every project is adaptive, so rates go up) or too restrictive (no project is adaptive, so no adaptation investment). It also leaves open critical questions about who should fund what. For example, should wildfire insurance be funded through electricity rates or through an outside source? And how should that be determined?

\section{OVERVIEW OF THE COMMISSION'S CLIMATE ADAPTATION REGULATION AND PROCESS}

The Commission issued a final decision on August 27, 2020. Much of the decision offers general guidance for the utilities about how to plan for climate change ${ }^{10}$. It also requires some key specific action on the part of utilities. Fist, private energy utilities in California must complete and file climate vulnerability assessments every 4 years. The vulnerability assessments at minimum must consider climate impacts to infrastructure, potential ways to manage climate risk, and include a discussion of how climate change impacts marginalized and vulnerable

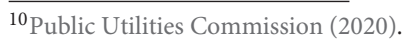

communities $^{11}$. within their service territories. The decision requires utilities to focus on the next 20-30 year time frame for impacts, while including an intermediate 10-20 year time frame and a long-term 30-50 year time frame. Strikingly, the decision requires personnel changes within the utilities; they must each create cross departmental "climate change teams" that report independently to the senior vice president level or above. Board members likewise are instructed to take responsibility for climate adaptation planning for infrastructure, operations, and services. The decision left open the possibility of allowing the energy utilities to recoup costs for vulnerability assessments and climate adaptation measures through General Rate Cases. The decision, however, does not establish standards or guidance on how to evaluate whether measures proposed by utilities are adaptive, maladaptive, or irrelevant to climate adaptation.

Because the Commission categorized the climate adaptation proceeding as quasi-legislative, as opposed to quasi-judicial, there was significant flexibility in how the Commission could develop the record in this proceeding. Behind the Commission's decision was a multi-year engaged stakeholder process, with in-person facilitated workshops, reports, and opportunities for written comments. These meetings were broken down in to a handful of topics: (1) what should the definition of climate change adaptation be in the context of private energy utilities ${ }^{12},(2)$ what

\footnotetext{
${ }^{11}$ The Decision refers to these communities as "Disadvantaged Vulnerable Communities" or "DVCs." The Decision uses a state environmental justice screening tool, CalEnviroScreen, to determine which communities constitute DVCs; specifically they are those communities with $25 \%$ highest scoring census tracts; all tribal lands; census tracts with median household incomes less than $60 \%$ of state median income; and census tracts that score in the highest 5\% of Pollution Burden within CalEnviroScreen.

${ }^{12}$ Southern California Edison (2019).
} 
data sources, models, and tools the utilities could or should use to plan for climate adaptation ${ }^{13}$, (3) how to include consideration of vulnerable and disadvantaged communities ${ }^{14}$, and (4) what the decision making, or risk consideration, framework should be for climate adaptation $^{15}$.

The timing of these meetings is notable. The first workings group meeting to discuss regulating climate adaptation and energy utilities was held in San Francisco on January 25, 2019. Four days later, and one block to the north, Pacific Gas and Electric Co. would file for bankruptcy after the most destructive wildfire in the State's history to date. The wildfires and the bankruptcy were taboo topics at the meetings, with specific instructions from the Commission staff to not address either.

Meetings were run by Commission Staff, who usually began the sessions with a specific proposal and then asked the participating parties to comment. Many of the workshops also made use of outside facilitators, usually from other state agencies which had more experience in climate adaptation policy. Expertise among participants varies. The three largest utilities sent teams of engineers, risk managers, government relations staff, and occasionally DEI staff. A variety of environmental organizations participated, though could not spare as much staff or time to the proceeding-each sending usually one personwith the exception of the California Environmental Justice Alliance, which makes good use of law students to staff agency participation. And the Commission's independent consumer advocates branch sent between one and three people, depending on other staff constraints (for a complete list of participants, see Reports 1-4).

Utility representation dominated the working groups, not only because of their greater numbers. To develop the record, the Commission needed written reports from the working group sessions. But assigned the job of notetaking and report writing to the utilities ${ }^{16}$. It should be noted that the utilities themselves along with other participants protested this assignment. Although there was an opportunity to correct accidental misrepresentations, the reports were put together under difficult circumstances by non-expert note takers, representing businesses that had a financial stake in the outcome of the proceeding. However, as part of the process leading up to the decision, each report was formally adopted by the Commission, with an opportunity for written comments.

\section{STRUCTURAL LIMITATIONS OF THE COMMISSION'S PROCESS}

As the first Public Utilities Commission to regulate climate adaptation by private energy utilities, the Commission should be lauded. But, the Commission's failure to establish guidance or standards by which to evaluate climate adaptation means

\footnotetext{
${ }^{13}$ Pacific Gas Electric (2019b).

${ }^{14}$ Pacific Gas Electric (2019a).

${ }^{15}$ This last working group also included elements of a cancelled working group (formerly group 3 ) on the question of how to coordinate climate adaptation across multiple proceedings within the Commission. Southern California Gas Company (2019).

${ }^{16}$ California Public Utilities Commission (2020).
}

that the attempt to regulate didn't address the most important question. While the Commission is best positioned to regulate climate adaptation in the private energy sector, it is ill equipped to do so. As other regulators look to tackle climate adaptation, there are some structural limitations that we should be sober and direct about, which repeatedly hampered the Commission's process, making it perhaps too challenging to address critical fundamental questions about climate adaptation for regulated utilities. We discuss what we found to be the most significant and pernicious limitations here: competing interests, capacity, and scope of the problem.

\section{Competing Interests}

Public oversight of private industry is premised on the idea that there would be competing interests. The firm is designed to maximize profits, the regulator is supposed to protect the public from the excesses of the firm's attempts to maximize. There are institutional incentives for organizations' representatives to act to further these goals. Hence, utilities regularly supported guidance that would limit oversight and increase ways to collect money from rates. For example, as discussed below, Pacific Gas and Electric Company was eager to have a flexible definition of climate adaptation and all three of the large utilities sought to limit climate adaptation to hard infrastructure-for which they can collect a return on investment-and not for "soft infrastructure," like changing maintenance schedules or considering staffing changes - for which utilities cannot collect a return on investment.

Bounded rationality among individual participants was also tied to more personal competing interests. It is not surprising that a hypothetical electrical engineer specializing in transmission line capacity would not be enthusiastic about a requirement for community engagement, and instead hope to focus the conversation on topics within their area of expertise. Given that there was limited time and resources to conduct and learn from adaptation workshops, the initial bounded rationality of participants dictated the content of the workshop outcomes.

In other words, the stated common goal of climate adaptation was not overarching in reality. Where adaptation would conflict with core institutional and individual interests, those nonadaptation interests controlled. What is concerning about this otherwise mundane fight over interests is that climate change is an existential threat-but we can't help ourselves, on an individual and organizational level, to keep fighting the same old fights.

\section{Capacity}

The Commission has a large staff, roughly 1,000 people, who deal with a wide variety of issues-from determining wildfire liability for electric utilities to regulating energy efficiency programs. Multiple staff work on the same proceeding through the proceeding's duration. Staff are frequently shuffled from one proceeding to another as they get promoted, are reassigned, or due to turnover. As a result, relatively new staffwith limited access to institutional memory-sometimes end up being tasked with managing complex proceedings like climate adaptation. 
Although staff turnover impacts most aspects of the Commission's work, the Commission has built up institutional knowledge for most of its work areas. Unfortunately, climate adaptation is a new and complex work area. There was little to no in-house expertise. Staff therefore ended up relying on the most active stakeholders in the proceeding-e.g., the IOUs, which have institutional capacity and a financial interest in the outcome of the proceeding.

\section{Scope}

The size of the problem may be too big. There are two attributes of climate impacts that would regularly stall out dialogue during the working group process. First, climate impacts are crosscutting. Climate impacts tend to not confine themselves to one economic sector or another. Extreme heat and sea level rise do not "target" utility infrastructure to the exclusion of other industry, communities, or ecosystems. This allowed an opening for parties to suggest that the issue was beyond their jurisdiction. Second, climate impacts-especially those in a $+3 \mathrm{C}$ or $+4 \mathrm{C}$ world-are scary. When faced with a question about how a utility should plan for or respond to a massive exodus of its ratepayers over time-e.g., people moving out of California because houses and businesses are literally underwater, or wildfires become intolerable $^{17}$, or it simply becomes too hot-the response from parties was that those scenarios were such existential threats that it was not worth thinking about. This made it difficult, if not impossible, to discuss and plan for worst case scenarios.

\section{ACTIONABLE RECOMMENDATIONS}

- Regulatory Commissions should regulate climate adaptation by private utilities. The commissions are best positioned to guide and oversee adaptation in the private energy sector, because they have experience in and authority to review utility decisions in light of public interest. The IOUs are best positioned to make investments and act to mitigate climate risks. They also have a vested interest to spend as much as they can on hard infrastructure. But, from an energy equity and climate mitigation perspective, there is a need to keep energy costs down. Regulatory Commissions are meant to do exactly that.

- To overcome some of the structural limitations discussed above, regulatory commissions need to invest in expertise and staff capacity to have the authority and know-how to regulate and oversee private energy sector adaptation, and push back on IOU emphasis on hard infrastructure

\footnotetext{
${ }^{17}$ USA Today (2019).
}

\section{REFERENCES}

Auffhammer, M., Baylis, P., and Hausman, C. H. (2017). Climate change is projected to have severe impacts on the frequency and intensity of peak electricity demand across the United States. Natl. Acad. Sci. 114, 1886-1891. doi: $10.1073 /$ pnas.1613193114

Burillo, D., Chester, M. V., Pincetl, S., and Fournier, E. (2019). Electricity infrastructure vulnerabilities due to long-term growth and extreme heat
- Regulatory commissions and IOUs need additional funding from outside the electric sector to (1) build up expertise on this subject and (2) to fund upgrades to energy infrastructure for the purpose of adaptation. Two possible avenues for this funding are:

- A new federal grant-making process to fund climate adaptation action for energy utilities

- State legislative action to identify an appropriate source of money for a climate adaptation fund. For example increased carbon fees on polluters ${ }^{18}$.

- Commissions undertaking a climate adaptation regulation should develop a framework to:

- Establish guidelines and standards by which to evaluate whether a measure should be considered adaptation, and if so

- determine whether and how such measures should be funded by ratepayers as opposed to from outside the electric sector.

\section{CONCLUSION}

To enable regulatory commissions to successfully oversee climate adaptation of the energy sector in California, advancements in policy, regulatory structures, and analytical expertise are needed. New analytical expertise is required to identify climate risks and determine cost-effective investments in utility procurement, operations, and infrastructure to adapt the energy sector to climate change while continuing to reduce the energy sector's carbon impact. Regulatory advancements are necessary to determine how commissions should oversee and guide IOU spending on climate adaptation to minimize climate risk costeffectively. Policy advancements are necessary to identify new sources of funding for these investments so that all costs of mitigation and adaptation aren't loaded on to the price of electricity, which must remain affordable to meet our climate goals; and to empower commissions to take on this new responsibility.

\section{AUTHOR CONTRIBUTIONS}

All authors listed have made a substantial, direct, and intellectual contribution to the work and approved it for publication.

\footnotetext{
${ }^{18}$ California already has a precedent for this: California Climate Investments spend revenue collected from the state's cap-and-trade system on environmental and public health initiatives in the state's disadvantaged communities. California Climate Investments. Cap-and-Trade Dollars at Work. Available online at: http:// www.caclimateinvestments.ca.gov/ (accessed May 21, 2021).
}

from climate change in Los Angeles County. Energy Policy 128, 943-953. doi: 10.1016/j.enpol.2018.12.053

California Office of Environmental Health Hazard Assessment (2017). Disadvantaged Community Designation. Available online at: https://oehha.ca. gov/calenviroscreen/sb535 (accessed May 21, 2021).

California Office of Environmental Health Hazard Assessment (2019). Extreme Heat Events. Available online at: https://oehha.ca.gov/epic/changes-climate/ extreme-heat-events (accessed May 21, 2021). 
California Public Utilities Commission (2020). Proposed Decision on Energy Utility Climate Change Vulnerability Assessments and Climate Change Adaptation in Disadvantaged Communities (Phase 1, Topics 4 and 5). Available online at: https://docs.cpuc.ca.gov/PublishedDocs/Efile/G000/M342/ K080/342080840.PDF (accessed May 21, 2021).

Chhabra, M., and Hay, C. (2020). The impact of wildfires and beneficial electrification on electricity rates in PG\&E's service territory. Electricity J. 33:3. doi: $10.1016 /$ j.tej.2020.106710

Franco, G., and Sanstad, A. H. (2008). Climate change and electricity demand in California. Climatic Change 87, 139-151. doi: 10.1007/s10584-007-9 364-y

National Public Radio (2019). The Camp Fire Destroyed 11,000 Homes. A Year Later Only 11 Have Been Rebuilt. Available online at: https://www.npr.org/ 2019/11/09/777801169/the-camp-fire-destroyed-11-000-homes-a-year-lateronly-11-have-been-rebuilt (accessed May 21, 2021).

Natural Resources Defense Council (2019). California Enacts Major Utility Wildfire Reforms. Available online at: https://www.nrdc.org/experts/alexjackson/california-enacts-major-utility-wildfire-reforms (accessed May 21, 2021).

Pacific Gas and Electric (2019a). Order Instituting Rulemaking to Consider Strategies and Guidance for Climate Change Adaptation (R.18-04-019): Working Group Session Report on Item "Climate Vulnerable and Disadvantaged Communities". Available online at: https://docs.cpuc.ca.gov/PublishedDocs/ Efile/G000/M303/K074/303074259.PDF (accessed May 21, 2021).

Pacific Gas and Electric (2019b). Order Instituting Rulemaking to Consider Strategies and Guidance for Climate Change Adaptation (R.18-04-019): Working Group Session Report on Item "Data Sources, Models, and Tools". Available online at: https://docs.cpuc.ca.gov/PublishedDocs/Efile/G000/M273/ K147/273147204.PDF (accessed May 21, 2021).

Pacific Gas and Electric Company (2016). Climate Change Vulnerability Assessment. Available online at: https://www.pgecurrents.com/wp-content/ uploads/2016/02/PGE_climate_resilience.pdf (accessed May 21, 2021).

Public Utilities Commission (2020). Proposed Decision on Energy Utility Climate Change Vulnerability Assessments and Climate Adaptation in Disadvantaged Communities (Phase 1, Topics 4 And 5). Available online at: https://docs.cpuc. ca.gov/PublishedDocs/Published/G000/M345/K700/345700383.PDF (accessed May 21, 2021)
Seattle City Light (2015). Climate Change Vulnerability Assessment and Adaptation Plan. Available online at: https://www.seattle.gov/light/enviro/docs/Seattle City_Light_Climate_Change_Vulnerability_(accessed May 21, 2021).

Southern California Edison (2019). Order Instituting Rulemaking to Consider Strategies for Climate Change Adaptation (R.18-04-019): Working Group Session Report on Item "Definition of Adaptation for Utilities". Available online at: https://docs.cpuc.ca.gov/PublishedDocs/Efile/G000/M261/K792/ 261792756.PDF (accessed May 21, 2021).

Southern California Gas Company (2019). Order Instituting Rulemaking to Consider Strategies and Guidance for Climate Change Adaptation (R.1804-019): Working Group Session Report on Topic 5 "Climate Change Adaptation Decision-Making Framework". Available online at: https://docs. cpuc.ca.gov/PublishedDocs/Efile/G000/M324/K941/324941939.PDF (accessed May 21, 2021).

USA Today (2019). Northern California Town of Paradise Post 90\% of Its Population After Camp Fire, Data Shows. Available online at: https://www. usatoday.com/story/news/nation/2019/07/11/paradise-california-populationcamp-fire-california-wildfire-fund/1710525001/ (accessed May 21, 2021).

Conflict of Interest: The authors declare that the research was conducted in the absence of any commercial or financial relationships that could be construed as a potential conflict of interest.

Publisher's Note: All claims expressed in this article are solely those of the authors and do not necessarily represent those of their affiliated organizations, or those of the publisher, the editors and the reviewers. Any product that may be evaluated in this article, or claim that may be made by its manufacturer, is not guaranteed or endorsed by the publisher.

Copyright $\odot 2021$ Ziaja and Chhabra. This is an open-access article distributed under the terms of the Creative Commons Attribution License (CC BY). The use, distribution or reproduction in other forums is permitted, provided the original author(s) and the copyright owner(s) are credited and that the original publication in this journal is cited, in accordance with accepted academic practice. No use, distribution or reproduction is permitted which does not comply with these terms. 